\title{
FROM NEEDS ANALYSIS TO DESIGNING ACADEMIC WRITING MATERIALS FOR DIPLOMA STUDENTS OF MARA UNIVERSITY OF TECHNOLOGY (UITM), MALAYSIA
}

\author{
Nancy Chiuh@ Noemi \\ Universiti Teknologi MARA Sabah, Malaysia \\ nancychiuh@sabah.uitm.edu.my
}

\begin{abstract}
When students begin their undergraduate studies, they will need to adjust to the demands of the undergraduate studies with regard to academic English at university level. Dudley-Evans \& St. John $(1998$, p.37) maintain that "their English tuition up to the tertiary level will generally have been in the area of General English, and is unlikely to have included specific preparation for study at university level...” Barker (2000, p.8), in his study on first year students' perception of writing difficulties, found that the students "come to realise during first semester that they are not adequately prepared for the writing demands required at university". Pecorari (as cited in Phakiti \& Li, 2011) found that Asian ESL students had problems in academic writing; "the students begin their aca-demic writing from 'copying' which implies a lack of training in academic writing and arouses accusations of plagiarism in their writing” (p.232). Being an English-medium public university in Malaysia, MARA University of Technology (UiTM) poses challenges to both its students and instructors, as a good command of English is essential. In its attempt to equip its undergraduate students with language skills, UiTM has introduced credit-bearing English courses. This paper presents the findings from a research project to identify the academic writing needs of first-year Diploma in Public Administration students in UiTM Sabah. A total of 110 Diploma in Public Administration students and six instructors responded to the questionnaires. The research examined the students' and instructors' perceptions of the importance of academic writing skills the students need in order to complete their undergraduate programmes, assessment of the students' academic writing skills, and the difficulty of academic writing skills. The findings indicated that there was consistency of response between the students and instructors. The follow-up interviews and focus groups with instructors and students confirmed this. The findings from the needs analysis are then used as the basis for developing academic writing materials to complement the existing English courses in UiTM.
\end{abstract}

Keywords: Needs analysis; academic writing; academic writing materials.

Students will need to adjust to the English used at university level when they begin their undergraduate studies. Dudley-Evans and St. John (1998) maintain that "their English tuition up to the tertiary level will generally have been in the area of General English, and is unlikely to have included specific preparation for study at university level...” Cline, Bissell and Hafner (2007) argued that "the focus in high schools has been primarily on college eligibility requirement”. They identified a gap in academic skills between high schools and universities. English language courses for example English for academic purposes (EAP) courses are offered in institutes of higher education where English is the medium of instruction. EAP, in higher education setting, aims at training students to use language appropriately for study. Thus EAP was probably developed to fill the gap between high schools and universities with regard to English used at university level. However, were the real 
needs of the students taken into account when designing EAP courses, or were they designed based merely on assumptions on what the students need?

This paper reports on the findings from a research project to identify the academic writing needs of the first-year Diploma in Public Administration (DPA) students in UiTM Sabah. The study examined the perceptions of DPA students and instructors on the importance of academic writing skills required for successful course completion in an undergraduate programme. The study also explored the assessment of the students' academic writing skills from the perspectives of both DPA students and instructors. The study further investigated the difficulties DPA students faced in preparing assignments for their instructors and identifies additional help the students need. This paper reports on the data collected from the questionnaire only.

\section{Needs Analysis}

Various studies (for example, Bosher and Smalkoski, 2002; Holliday, 1995; Jasso-Aguilar, 1999; Li So-mui and Mead, 2000) stressed the importance of conducting a needs analysis to better identify the real needs of the subjects which eventually lead to more focused courses. When the real needs of the learners are identified, more focused courses can be designed to meet these needs and the learners are able to benefit fully from these courses.

"The foundation of all ESP is the simple question: Why does this learner need to learn a foreign language? From this question will flow a whole host of further question, some of which will relate to the learners themselves, some to the nature of the language the learners will need to operate, some to the given learning context. But this whole analysis derives from an initial identified need on the part of the learner to learn a language. ESP, then, is an approach to language teaching in which all decisions as to content and method are based on the learners' reason for learning” (Hutchinson \& Waters, 1987, p19). ). "The job of the EAP lecturer is to find out what the students have to do and help them to do it better" (Gillett, 1996, Introduction section, para. 1). Tomlinson (2003, p3) maintained that "the needs and wants of the learners should drive the materials". He further stated that teachers and administrators have their needs and wants to be satisfied too.

\section{EAP Needs in Higher Institutions of Learning}

Studies in higher institutions (e.g. Chiuh \& Lee, 2012; Huang, 2010; Barker, 2000) have revealed that writing was considered as the most important skill or a major problem for students. Huang (2010) carried out a research project on the academic writing needs of graduate and undergraduate students of a new academic language support centre at a Canadian university. She found that the writing skills were considered as needing more help than the other skill domains based on undergraduate students' self-assessment. Graduate students also ranked writing as the most important skill domain that needs further development. In a more recent study on EAP students in UiTM Sabah, Chiuh and Lee (2012) also found the writing skill as the weakest skill as and in need of more help than the other language skills. These studies were further supported by Barker (2000) in his study on 74 first year students in an Australian university. He found that students discovered that they were not adequately prepared for writing at university. They experienced increasing difficulties with writing tasks. 
Several studies have revealed that English courses offered in higher institutions did not meet the needs of the students. Evans and Morrison (2011, p.206) in their study on first-year students in an English-medium higher education in Hong Kong found that 'the essentially generic EAP course undertaken by the participants was barely able to meet their immediate let alone long-term need'. Dehnad et al. (2010) also found discrepancy between what the students expressed as their needs and what is actually in the syllabus prescribed by the Ministry of Health in Iran. In investigating the EAP needs of engineering students in the British Malaysia Institute, Kuala Lumpur, Wan (2002) found inconsistencies between the students' perceived needs and the real needs in the engineering context. Bosher and Smalkoshi (2002) reported a needs analysis conducted on ESL nursing students at the Minneapolis campus of the College of St. Catherine. The analysis was in response to the faculty concern about the difficulty many of these ESL students were having in succeeding academically in their degree nursing programme. A course was developed to meet the identified objective, subjective and learning needs of these students and was successful.

\section{UiTM Context}

Since English is the medium of instruction in MARA University of Technology (UiTM), it is imperative for instructors and students to use the language in the teaching and learning process. Students need to possess a certain level of English proficiency in order to excel in their studies in UiTM. In its attempt to equip its undergraduate students with the academic language skills, UiTM has introduced credit-bearing English courses. ELC120 (Integrated Language Skills: Listening) and ELC150 (Integrated Language Skills: Reading) are the two English courses compulsory for first-year diploma students across the disciplines in UiTM. Both courses carry three credit units and the students study the courses for 14 consecutive weeks each.

\section{METHOD}

\section{Participants \\ Students}

The subjects of the study were first-year students of Diploma in Public Administration in UiTM Sabah campus for semester June-September 2013. The subjects were chosen from one programme only because the gathered data are used as the basis for designing and developing discipline-specific academic writing materials. The whole population of 110 students were taken in this study. There were 71 females and 39 males.

\section{Instructors}

The instructors chosen as respondents for this study were those who taught the DPA students for semester June-September 2013. Six out of 7 DPA instructors responded to the questionnaire. Their experience in teaching DPA students in UiTM ranged from one year to more than 10 years. 


\section{Questionnaire}

The questionnaire used in the study was adapted from Rosenfeld, Leung and Oltman's (2001) research. It contained reading, writing, speaking and listening tasks considered to be important for competent academic performance of undergraduate and graduate students. The questionnaire was modified to suit the objectives of the present study. The adapted questionnaire contained writing tasks only. Some new items were added to the questionnaire. Three sections were added to include assessments of students' writing skills, difficulty in performing writing tasks and comment on whether additional help was needed. The background section was modified to reflect the university context. Some tasks which thought irrelevant to the present study were removed. The modified questionnaire consisted of five sections: (1) the respondent's background information (2) the importance of writing tasks for academic performance, (3) a self-assessment of ability in writing tasks, (4) difficulty in performing writing tasks, and (5) comment on whether additional help was needed. The instructors' questionnaire contained the same categories, but the item stems read 'How important is it for your students...', 'How well can your students...' and 'How difficult is it for your students...' instead of 'How important is it for you...', 'How well can you...' and 'How difficult is it for you...'.

\section{Initial and Final Piloting}

The modified questionnaire was first piloted to an instructor with teaching experience of more than 20 years. The purpose of the pilot test was to determine if the survey instrument and its directions were clear and easy to use. The initial piloting was also aimed at locating irrelevant items. The instructor has located unclear instructions and items which are irrelevant to the present study. Changes were made after reviewing the comments from the instructor. The revised version of the questionnaire was then administered to a group of 24 DPA students, which was similar to the target population under study. The researcher was present while the group was completing the questionnaire. Dörnyei (2003) so realistically stated that being present at the piloting stage, the researcher "can observe their reactions (e.g., hesitations or uncertainties) and can note and respond to any spontaneous questions or comments” (p.66). The students took 20 minutes to complete the questionnaire.

\section{RESULT}

To assess the questionnaire's internal consistency reliability, the Cronbach's alpha statistics were computed for each section of the questionnaire. Cronbach alpha's reliability coefficient is a figure ranging between 0 and 1 . George and Mallery (as cited in Gliem and Gliem, 2003, p. 87) provide the following rules of thumb for reliability values: “_> .9- Excellent, _> .8 - Good, _> .7 - Acceptable, ${ }_{-}>.6$ - Questionable, _> .5 - Poor and _ $<.5$ - Unacceptable”. The results showed values ranging from 0.90 to 0.91 (table 1 ).

Table 1. Results from the Cronbach's alpha statistics for the questionnaires' internal

\begin{tabular}{lccc}
\hline $\begin{array}{l}\text { consistency reliability } \\
\text { Respondent }\end{array}$ & $\begin{array}{l}\text { Importance of } \\
\text { Writing Skills }\end{array}$ & $\begin{array}{c}\text { Status of } \\
\text { Writing Skills }\end{array}$ & Difficulty of Writing Skills \\
\hline DPA Students & 0.91 & 0.90 & 0.91 \\
\hline
\end{tabular}


To establish content validity, the questionnaire was given to an instructor with vast experience of teaching the English language and an experienced EAP instructor to comment. Based on their comments, the questionnaire examined the full scope of the research questions in a balanced way and matched the actual situation that was being studied; i.e. it measured the academic writing needs of DPA students.

To assess the acceptability of the questionnaire, in the pilot study, a group of 24 respondents were asked to give their comments on a separate sheet of paper.

\section{Final Administration}

The comments obtained from the piloting stage were considered and only minor changes were necessary. The final questionnaire consisted of 60 items. The complete questionnaire was distributed to all four DPA groups of 110 students by the researcher. All four DPA groups completed and returned the questionnaire. As for the instructors' questionnaire, six out of seven DPA instructors completed the questionnaire.

\section{DISCUSSION}

SPSS version 20 was used to analyse the data for the students' and instructors' questionnaires. The study used the cut-off points in Huang's (2010) study where "a mean rating of 4.00 or higher ('very important') provides a firmer basis and clearer reference point for considering academic language skills' relatedness than a cut-off point of 3.00 ('important') or higher...As for the language skill status section, mean ratings below 3.00 indicate areas where respondents reported needing help in writing skills” (p.523). Huang gave the reasons for the selection of a mean rating of 4.00 or higher ('very important') as it "provides a firmer basis and clearer reference point for considering academic language skills' relatedness than a cut-off point of 3.00 ('important') or higher" and "those tasks that were rated as 'very important' could be easily identified for consideration in course or workshop development” (p.523). On the other hand, Rosenfeld et al. (2001) decided on the cut-point 3.50 or higher ('very important') and the mean ratings that rounded to 3.00 were classified as 'important'. Like Rosenfeld et al., Huang stated that all judgmental standards may be subject to debate. Rosenfeld et al. classified the cut-off point of 3.50 or higher ('very important') as it "provides a solid foundation for claims of job relatedness" (p.12) and also the cut-off point of 3.50 could ease test developers to identify 'very important' tasks.

\section{Importance of Writing Skills DPA Students' Perspectives}

The DPA students rated three writing tasks as 'very important' (Table 2) and 15 as 'important' on the questionnaire for satisfactory completion of their courses in their programmes (Table 3).

Table 2. Writing tasks rated 4.0 and above ('very important') by DPA students

\begin{tabular}{lccc}
\hline \multicolumn{1}{c}{ Writing tasks } & $\boldsymbol{M}$ & $\boldsymbol{S E}$ & $\boldsymbol{S D}$ \\
\hline Write in correct grammar & 4.23 & .092 & .964 \\
\hline Write in correct sentence structure & 4.19 & .090 & .943 \\
\hline Use relevant reasons and examples to support a position or idea & 4.00 & .079 & .824 \\
\hline
\end{tabular}

Note: $\mathrm{N}=110$ 
Table 3. Writing tasks rated above 3.0 ('important') by DPA students

\begin{tabular}{lccc}
\hline \multicolumn{1}{c}{ Writing tasks } & $\boldsymbol{M}$ & $\boldsymbol{S E}$ & $\boldsymbol{S D}$ \\
\hline Use appropriate subject-specific vocabulary & 3.98 & .095 & .995 \\
\hline Write thesis statement, topic sentences and supporting details & 3.89 & .091 & .952 \\
\hline Use sources appropriately to support ideas & 3.89 & .083 & .864 \\
\hline Use appropriate transitions to connect ideas and information & 3.84 & .089 & .934 \\
\hline Summarise information from secondary sources & 3.83 & .085 & .887 \\
\hline Organise writing in order to convey main and supporting ideas & 3.83 & .089 & .937 \\
\hline Acknowledge sources of information using in-text citations and references (e.g. & 3.60 & .084 & .873 \\
APA style) & & & \\
\hline Paraphrase information from secondary sources & 3.48 & .081 & .854 \\
\hline Write in response to an assignment and stay on topic without excessive & 3.45 & .082 & .863 \\
wordiness & & & \\
\hline Revise an academic text & 3.45 & .082 & .863 \\
\hline Synthesise information from secondary sources & 3.42 & .093 & .971 \\
\hline Edit an academic text & 3.37 & .087 & .917 \\
\hline Draft an academic text & 3.36 & .086 & .906 \\
\hline Write an outline of an academic text & 3.35 & .076 & .797 \\
\hline $\begin{array}{l}\text { Write in response to an assignment and stay on topic without } \\
\text { repetition in expression }\end{array}$ & 3.30 & .083 & .866 \\
\hline
\end{tabular}

Note: $\mathrm{N}=110$

\section{DPA Instructors' Perspectives}

DPA instructors rated all 10 writing tasks as 'very important' (Table 4) and 'important' (Table 5).

Table 4. Writing tasks rated 4.0 and above ('very important') by DPA instructors

\begin{tabular}{lccc}
\hline \multicolumn{1}{c}{ Writing tasks } & $\boldsymbol{M}$ & $\boldsymbol{S E}$ & $\boldsymbol{S D}$ \\
\hline $\begin{array}{l}\text { Acknowledge sources of information using in-text citations and references (e.g. } \\
\text { APA style) }\end{array}$ & 4.83 & .167 & .408 \\
\hline Use sources appropriately to support ideas & 4.83 & .167 & .408 \\
\hline Use relevant reasons and examples to support a position or idea & 4.50 & .224 & .548 \\
\hline Paraphrase information from secondary sources & 4.50 & .224 & .548 \\
\hline Organise writing in order to convey main and supporting ideas & 4.33 & .333 & .816 \\
\hline Synthesise information from secondary sources & 4.17 & .307 & .753 \\
\hline Write in response to an assignment and stay on topic without excessive wordiness & 4.17 & .307 & .753 \\
\hline Write thesis statement, topic sentences and supporting details & 4.00 & .365 & .894 \\
\hline Summarise information from secondary sources & 4.00 & .365 & .894 \\
\hline $\begin{array}{l}\text { Write in response to an assignment and stay on topic without } \\
\text { repetition in expression }\end{array}$ & & \\
\hline
\end{tabular}

$$
\text { Note: } \mathrm{N}=6
$$

Table 5. Writing tasks rated above 3.0 ('important') DPA instructors

\begin{tabular}{lccc}
\hline \multicolumn{1}{c}{ Writing tasks } & $\boldsymbol{M}$ & $\boldsymbol{S E}$ & $\boldsymbol{S D}$ \\
\hline Write in correct sentence structure & 3.83 & .167 & .408 \\
\hline Edit an academic text & 3.83 & .167 & .408 \\
\hline Use appropriate subject-specific vocabulary & 3.67 & .211 & .516 \\
\hline Write in correct grammar & 3.67 & .211 & .516 \\
\hline Draft an academic text & 3.67 & .333 & .816 \\
\hline Revise an academic text & 3.50 & .224 & .548 \\
\hline Use appropriate transitions to connect ideas and information & 3.50 & .224 & .548 \\
\hline Write an outline of an academic text & 3.33 & .333 & .816 \\
\hline
\end{tabular}

$$
\text { Note: } \mathrm{N}=6
$$

In the present study, the DPA students rated three writing tasks as very important and another 15 as important on the questionnaire for satisfactory completion of their courses in their programmes. DPA instructors rated all 10 writing tasks as very important in contrast to the ratings of the DPA students. The present study's findings 
is compared to Huang's (2010) and Rosenfeld et al.’s (2001) studies. The writing task which was shared between the three studies rated as 'very important' by the students was 'use relevant reasons and examples to support a position or idea'. This was also judged as 'very important' by the DPA instructors in the present study.

\section{Status of Writing Skills}

\section{DPA Students' Perspectives}

The DPA students rated all the writing tasks below 2.0 (Table 6).

Table 6 . Writing tasks rated below 2.0 by DPA students

\begin{tabular}{llcc}
\hline \multicolumn{1}{c}{ Writing tasks } & $\boldsymbol{M}$ & SE & SD \\
\hline $\begin{array}{l}\text { Write in response to an assignment and stay on topic without excessive } \\
\text { wordiness }\end{array}$ & 1.64 & .053 & .554 \\
\hline $\begin{array}{l}\text { Acknowledge sources of information using in-text citations and references } \\
\text { (e.g. APA style) }\end{array}$ & 1.66 & .061 & .639 \\
\hline $\begin{array}{l}\text { Write in response to an assignment and stay on topic without repetition in } \\
\text { expression }\end{array}$ & 1.68 & .053 & .557 \\
\hline Use appropriate subject-specific vocabulary & & & \\
\hline Paraphrase information from secondary sources & 1.68 & .068 & .716 \\
\hline Draft an academic text & 1.71 & .054 & .564 \\
\hline Synthesise information from secondary sources & 1.72 & .063 & .665 \\
\hline Write in correct grammar & 1.73 & .056 & .589 \\
\hline Edit an academic text & 1.74 & .063 & .659 \\
\hline Write an outline of an academic text & 1.75 & .066 & .693 \\
\hline Revise an academic text & 1.81 & .061 & .642 \\
\hline Write in correct sentence structure & 1.83 & .068 & .705 \\
\hline Use appropriate transitions to connect ideas and information & 1.84 & .063 & .657 \\
\hline Summarise information from secondary sources & 1.88 & .062 & .646 \\
\hline Write thesis statement, topic sentences and supporting details & 1.89 & .055 & .580 \\
\hline Organise writing in order to convey main and supporting ideas & 1.91 & .067 & .698 \\
\hline Use relevant reasons and examples to support a position or idea & 1.92 & .063 & .654 \\
\hline Use sources appropriately to support ideas & 1.95 & .063 & .661 \\
\hline
\end{tabular}

\section{DPA Instructors' Perspectives}

Like the undergraduate students, the DPA instructors also rated all 18 writing tasks below 2.0 (Table 7).

Table 7 . Writing tasks rated below 2.0 by DPA instructors

\begin{tabular}{lccc}
\hline \multicolumn{1}{c}{ Writing tasks } & $\boldsymbol{M}$ & $\boldsymbol{S E}$ & $\boldsymbol{S D}$ \\
\hline $\begin{array}{l}\text { Acknowledge sources of information using in-text citations and references } \\
\text { (e.g. APA style) }\end{array}$ & .33 & .211 & .516 \\
\hline Paraphrase information from secondary sources & .83 & .307 & .753 \\
\hline Revise an academic text & .83 & .167 & .408 \\
\hline Edit an academic text & .83 & .167 & .408 \\
\hline Summarise information from secondary sources & 1.00 & .516 & 1.265 \\
\hline Write an outline of an academic text & 1.00 & .258 & .632 \\
\hline Draft an academic text & 1.00 & .258 & .632 \\
\hline Synthesise information from secondary sources & 1.17 & .307 & .753 \\
\hline Write thesis statement, topic sentences and supporting details & 1.17 & .307 & .753 \\
\hline Use appropriate transitions to connect ideas and information & 1.17 & .307 & .753 \\
\hline Use sources appropriately to support ideas & 1.33 & .333 & .816 \\
\hline Write in correct grammar & 1.33 & .211 & .516 \\
\hline Write in correct sentence structure & 1.33 & .211 & .516 \\
\hline Write in response to an assignment and stay on topic without repetition & 1.50 & .224 & .548 \\
\hline Use relevant reasons and examples to support a position or idea & 1.50 & .224 & .548 \\
\hline
\end{tabular}




\begin{tabular}{lccc}
\hline Use appropriate subject-specific vocabulary & 1.50 & .224 & .548 \\
\hline $\begin{array}{l}\text { Write in response to an assignment and stay on topic without excessive } \\
\text { wordiness }\end{array}$ & 1.67 & .211 & .516 \\
\hline Organise writing in order to convey main and supporting ideas & 1.83 & .167 & .408 \\
\hline
\end{tabular}

Note: $\mathrm{N}=6$

The DPA students in the present study judged all writing tasks below 2.00, which suggesting in need of help in all the writing tasks. The findings in Huang's (2010) study indicated otherwise, in which the undergraduate respondents self-rated all the writing tasks in the questionnaire with a mean of above 3.00. Thus, suggesting not needing development in any skills. However, the EAP instructors in Huang's study who taught the undergraduate students rated 10 writing tasks below 3.00 as representing areas where students need the most help. In the present study, the DPA instructors agreed with the DPA students, in which they also rated all 18 writing tasks below 2.00. The needs of the undergraduates in Huang's study and the present study probably are different as the former study was conducted at a Canadian university and the latter study was carried out at a Malaysian university. Thus, it is crucial to conduct students' needs analysis, for "the students' needs may differ according to the learning environment” (Jordan, 1997, p.5).

\section{Difficulties in Writing Skills}

DPA Students' Perspectives

The undergraduate students rated all the writing tasks above 2.0 (Table 8).

Table 8 . Writing tasks rated above 2.0 by DPA students

\begin{tabular}{lccc}
\hline \multicolumn{1}{c}{ Writing tasks } & $\boldsymbol{M}$ & $\boldsymbol{S E}$ & $\boldsymbol{S D}$ \\
\hline $\begin{array}{l}\text { Acknowledge sources of information using in-text citations and references } \\
\text { (e.g. APA style) }\end{array}$ & 2.81 & .072 & .760 \\
\hline $\begin{array}{l}\text { Write in response to an assignment and stay on topic without repetition in } \\
\text { expression }\end{array}$ & 2.79 & .072 & .746 \\
\hline $\begin{array}{l}\text { Write in response to an assignment and stay on topic without excessive } \\
\text { wordiness }\end{array}$ & 2.79 & .071 & .759 \\
\hline Synthesise information from secondary sources & & & \\
\hline Summarise information from secondary sources & 2.77 & .070 & .738 \\
\hline Edit an academic text & 2.75 & .069 & .719 \\
\hline Paraphrase information from secondary sources & 2.70 & .072 & .752 \\
\hline Write in correct grammar & 2.68 & .071 & .741 \\
\hline Write an outline of an academic text & 2.65 & .085 & .893 \\
\hline Revise an academic text & 2.64 & .078 & .821 \\
\hline Use sources appropriately to support ideas & 2.61 & .077 & .802 \\
\hline Use appropriate subject-specific vocabulary & 2.61 & .078 & .817 \\
\hline Draft an academic text & 2.60 & .080 & .837 \\
\hline Write in correct sentence structure & 2.60 & .077 & .804 \\
\hline Write thesis statement, topic sentences and supporting details & 2.56 & .083 & .873 \\
\hline Use appropriate transitions to connect ideas and information & 2.54 & .083 & .874 \\
\hline Organise writing in order to convey main and supporting ideas & 2.54 & .077 & .809 \\
\hline Use relevant reasons and examples to support a position or idea & 2.53 & .076 & .798 \\
\hline
\end{tabular}

Note: $\mathrm{N}=110$

\section{DPA Instructors' Perspectives}

Like the undergraduate students, the DPA instructors also rated all 18 writing tasks above 2.0 (Table 9). 
Table 9 . Writing tasks rated above 2.0 by DPA instructors

\begin{tabular}{lccc}
\hline \multicolumn{1}{c}{ Writing tasks } & $\boldsymbol{M}$ & $\boldsymbol{S E}$ & SD \\
\hline Synthesise information from secondary sources & 4.17 & .167 & .408 \\
\hline $\begin{array}{l}\text { Acknowledge sources of information using in-text citations and } \\
\text { references (e.g. APA style) }\end{array}$ & 4.00 & .447 & 1.095 \\
\hline Paraphrase information from secondary sources & 3.83 & .401 & .983 \\
\hline Write in correct grammar & 3.67 & .333 & .816 \\
\hline Summarise information from secondary sources & 3.67 & .211 & .516 \\
\hline Edit an academic text & 3.50 & .224 & .548 \\
\hline Use sources appropriately to support ideas & 3.50 & .224 & .548 \\
\hline Write in correct sentence structure & 3.33 & .211 & .516 \\
\hline Revise an academic text & 3.17 & .167 & .408 \\
\hline Use relevant reasons and examples to support a position or idea & 3.17 & .307 & .753 \\
\hline Organise writing in order to convey main and supporting ideas & 3.17 & .167 & .408 \\
\hline Use appropriate subject-specific vocabulary & 3.17 & .307 & .753 \\
\hline Draft an academic text & 3.00 & .258 & .632 \\
\hline Write thesis statement, topic sentences and supporting details & 3.00 & .365 & .894 \\
\hline $\begin{array}{l}\text { Write in response to an assignment and stay on topic without repetition } \\
\text { in expression }\end{array}$ & 3.00 & .258 & .632 \\
\hline Write an outline of an academic text & & & \\
\hline Use appropriate transitions to connect ideas and information & 2.67 & .333 & .816 \\
\hline Write in response to an assignment and stay on topic without excessive \\
wordiness
\end{tabular}

Note: $\mathrm{N}=6$

The DPA students and instructors in the present study judged all writing tasks above 2.00, which suggesting they perceived all the writing tasks as difficult. The DPA students and instructors agreed on one task which is 'acknowledge sources of information using in-text citations and references (e.g. APA style)' as being one of the most difficult writing tasks.

\section{Additional Help in Academic Writing}

In the last section of the questionnaire, the DPA students and instructors were required to indicate whether the students need additional help in order to develop their academic writing skills aside from their English course(s) in UiTM. 83.6\% of 110 students indicated that they needed additional help to develop their academic writing skills and $5.5 \%$ of 110 students indicated otherwise. As for the instructors, five out of six responded to the question. All five indicated that their students needed additional help with their writing skills.

Based on the results of the whole questionnaire survey, it is apparent that the DPA students' and instructors' have quite common perspectives on the needs of the DPA students. There were also an agreement between the DPA students and instructors of the need for additional help in academic writing.

\section{CONCLUSION}

This study identified the academic writing needs of DPA undergraduate students from the perspectives of the students themselves and the DPA instructors. In an attempt to identify the real needs of the students, the researcher employed the triangulation of various methods and sources. The identified needs were then used 
as the basis for designing and developing discipline-specific academic writing materials. Identifying the real needs of subjects is no doubt crucial in designing courses, developing materials, writing syllabi, etc. as reported in various studies on needs analysis (for example, Bosher \& Smalkoski, 2002; Holliday, 1995; JassoAguilar, 1999; So-mui \& Mead, 2000). Even if there is already an existing course in an institution, one should not assume that it has successfully met the needs of the students. This study suggests that on-going needs analyses need to be conducted to ensure that courses meet the needs of learners.

\section{REFERENCES}

Barker, G. (2000). First-year students' perceptions of writing difficulties in science. Proceedings of the 1st year in Higher Education Conference, 2000, Queensland University of Technology, Brisbane, Australia.

Bosher, S. And Smalkoshi, K. (2002). From needs analysis to curriculum development: designing a course in health-care communication for immigrant students in the USA. English for Specific Purposes 21, 59-79.

Chiuh, N. \& Lee, K. W. (2012). Investigating the academic writing needs of English for academic purposes (EAP) students in UiTM. Proceedings of My_CASELT conference, 2000, Shah Alam, Malaysia.

Cline, Z., Bissell, J., Hafner, A. \& Katz, M. (2007). Closing the college readiness gap.

Leadership. Nov/Dec Vol. 37, Iss.2, Pg 30-33. Retrieved from http://proquest.umi.com/

Denhad, A., Bagherzadeh, R., Shoaleh Bigdeli, Hatami, k. \& Hosseini, F. (2010). Syllabus. Revision: a needs analysis study. Procedia Social and Behavioral Sciences 9, 1307-1312.

Dörnyei, Z. (2003). Questionnaires in Second Language Research: Construction, Administration, and Processing. New Jersey: Lawrence Erlbaum Associates.

Dudley-Evans, T. and St. John, M. J. (1998). Developments in English for Specific Purposes: A Multi-disciplinary Approach. Cambridge: Cambridge University Press.

Evans, M. \& Morrison, B. (2011). Meeting the challenges of English-medium higher education: The first-year experience in Hong Kong. English for Specific Purposes 30, 198-208.

Gillett, A. (1996). “What is EAP?” IATEFL ESP SIG Newsletter, 6, 17-23. 
Gliem, J. A. \& Gliem, R.R. (2003). Calculating, interpreting, and reporting Cronbach's.

Alpha Reliability Coefficient for likert-type scales. The Ohio State University, Midwest Research to Practice Conference in Adult, Continuing, and Community Education: 82-88, October 8-10 2003, Columbus. OH.

Holliday, A. (1995). Assessing language needs within an institutional context: an ethnographic approach. English for Specific Purposes 14(2), 115-126.

Huang, L. S. (2010). Seeing eye to eye? The academic writing needs of graduate and undergraduate students from students' and instructors' perspectives. Language Teaching Research 14(4), 517-539.

Hutchinson, W. And Waters, A. (1987) English for Specific Purposes. Cambridge: Cambridge University Press.

Jasso-Aguilar, R. (1999). Sources, methods and triangulation in needs analysis: a critical perspective in a case study of Waikiki hotel maids. English for Specific Purposes 18(1), 27-46.

Jordan, R. R. (1997). English for Academic Purposes: a Guide and Resource Book for Teachers. Cambridge: Cambridge University Press.

Li So-Mui, F. and Mead, K. (2000). An analysis of English in the workplace: the communication needs of textile and clothing merchandisers. English for Specific Purposes 19, 351-368.

Phakiti, A. and Li, L. (2011). General academic difficulties and reading and writing difficulties among Asian ESL postgraduate students in TESOL at an Australian university. RELC Journal 42, 227-264.

Rosenfeld, M., Leung, S. \& Oltman, P. K. (2001). The Reading, Writing, Speaking and Listening Tasks Important for Academic Success at the Undergraduate and Graduate Levels. TOEFL monograph 21. Princeton, NJ: Educational Testing Service.

Tomlinson, B. (ed.). (2003). Developing Materials for Language Teaching. London, Bloomsbury.

Wan, I. I. (2002). EAP English language needs analysis of engineering students in higher education (Unpublished dissertation). Universiti Putra Malaysia. 